\title{
Hypothalamic obesity due to hydrocephalus caused by aqueductal stenosis
}

\author{
N Suzuki, M Shinonaga, K Hirata, S Inoue, T Kuwabara
}

\begin{abstract}
A case is presented of 14 year old female with hypothalamic obesity due to hydrocephalus caused by aqueductal stenosis. Evidence of hypothalamic obesity included 1) acute hyperphagia and weight gain, 2) neuroradiology showed hydrocephalus with focal enlargement of the third ventricle, 3) endocrinological studies revealed hyperinsulinaemia and impaired growth hormone (GH) response to arginine, but normal GH response to growth hormone-releasing factor (GRF) and 4) Torkildsen's ventriculo-cisternal shunting resulted in improvement in hyperphagia and obesity.
\end{abstract}

Hypothalamic obesity is produced by bilateral destruction of ventromedial regions of the hypothalamus. ${ }^{1}$ Clinically it results from various organic diseases in the hypothalamus such as tumour, head trauma, inflammatory disease, and leukaemia. ${ }^{2}$ To our knowledge hydrocephalus due to aqueductal stenosis rarely causes this condition. We report the case of a young female with hypothalamic obesity due to hydrocephalus caused by aqueductal stenosis, which was improved by a Torkildsen's shunt.

\section{Case report}

A 15 year old female was admitted to the Yokahama City University Hospital for evaluation of obesity. She had suffered from meningiocephalitis at the age of three months and her weight increased after this episode. She did not walk until she was four years old probably because of sequela of meningiocephalitis and being overweight. Her height and weight were $133 \mathrm{~cm}$ and $63 \mathrm{Kg}$ at six years of age, and $145 \mathrm{~cm}$ and $67 \mathrm{Kg}$ at 13 years; within the next year she had an acute gain of $28 \mathrm{Kg}$ and weighed $95 \mathrm{Kg}$ at the age of 14. During this period she showed hyperphagia with a calorie intake of approximately $3000 \mathrm{kcal} /$ day.

On admission the patient's height was $147 \mathrm{~cm}$ and her weight was $89 \mathrm{Kg}$ (body mass index: 41 ). She was mentally retarded with an IQ of 57 . Her menarche had occurred at the age of seven and her menstruation had been irregular with hyper- and/or poly-menorrhea.

Endocrinological examination showed an impaired GH response to arginine but normal $\mathrm{GH}$ response to GRF in the preoperative state, and hyper-insulin response in $100 \mathrm{~g}$ oral glucose tolerance test (table).

Plain skull radiographs were normal. CT revealed cerebral atrophy and hydrocephalus with focal enlargement of the third ventricle. Metrizamide CT cisternography showed no reflux of the contrast material into the ventricular system and its clearance from the cistern was within normal limits. A metrizamide ventriculography was performed after placement of an Ommaya's reservoir, which showed focal stenosis of the cerebral aqueduct but no evidence of mass lesion in the third ventricle.

After admission, she was placed on $420 \mathrm{kcal}$ per day of semi-starvation treatment for seven weeks. At the end of this treatment her weight dropped $12 \mathrm{~kg}$, but her strong appetite still remained, resulting in hyperphagia (approximately $3000 \mathrm{kcal} /$ day) and weight gain when the semi-starvation treatment was stopped.

She then had a suboccipital craniectomy with a ventriculocisternal shunt (Torkildsen's procedure) using a Pudentz ventricular catheter.

Hyperphagia with strong appetite improved after the operation and her weight fell $6 \mathrm{~kg}$ in two weeks. Endocrinological studies one month after the operation revealed subnormal $\mathrm{GH}$ response to arginine and normal response to GRF (table). Insulin response to $100 \mathrm{~g}$ oral
Yokohama City
University School of Medicine, Yokohama, Japan

Department of

Neurological Surgery

N Suzuki

M Shinonaga

K Hirata

T Kuwabara

Third Department of Internal Medicine

$S$ Inoue

Correspondence to:

Dr Suzuki, Department of Neurological Surgery,

Yokohama City University

School of Medicine, 3-46,

School of Medicine, 3-46,

Urafune-cho, Minami-ku

Received .25 July 1989 and in

final revised form

14 February 1990

Accepted 5 April 1990
Table Changes of blood sugar, serum insulin (IRI) and growth hormone (GH) in various tests

\begin{tabular}{|c|c|c|c|c|c|c|c|c|}
\hline Time (minutes) & & 0 & 15 & 30 & 60 & 90 & 120 & 150 \\
\hline \multicolumn{9}{|c|}{ At admission (BW $89 \mathrm{~kg})$} \\
\hline \multicolumn{9}{|c|}{$100 \mathrm{~g}$ oral glucose tolerance test } \\
\hline $\begin{array}{l}\text { Blood Sugar }(\mathrm{mg} / \mathrm{dl}) \\
\text { IRI }(\mu \mathrm{U} / \mathrm{ml})\end{array}$ & & 86 & & 120 & 167 & 155 & 160 & \multirow{4}{*}{$3 \cdot 0$} \\
\hline Arginine stimulation & $\mathrm{GH}(\mathrm{ng} / \mathrm{ml})$ & $\begin{array}{r}23.3 \\
0.9\end{array}$ & & $\begin{array}{r}98 \cdot 1 \\
1 \cdot 0\end{array}$ & $\begin{array}{r}201.1 \\
1.0\end{array}$ & $\begin{array}{r}134.5 \\
0.9\end{array}$ & $\begin{array}{r}87 \cdot 1 \\
4 \cdot 6\end{array}$ & \\
\hline Levodopa stimulation & $\mathrm{GH}(\mathrm{ng} / \mathrm{ml})$ & $1 \cdot 1$ & & 1.5 & 1.7 & $1 \cdot 3$ & $\begin{array}{l}4.0 \\
1 \cdot 2\end{array}$ & \\
\hline GRF stimulation & $\mathrm{GH}(\mathrm{ng} / \mathrm{ml})$ & $2 \cdot 3$ & 37 & & 16 & $5 \cdot 0$ & $2 \cdot 4$ & \\
\hline \multicolumn{9}{|c|}{ After Tolkildsen's shunt (BW $68 \mathrm{~kg}$ ) } \\
\hline \multicolumn{9}{|c|}{$100 \mathrm{~g}$ oral glucose tolerance test } \\
\hline Blood Sugar (mg/dl) & & 80 & & 117 & 136 & 131 & 125 & \multirow{5}{*}{$2 \cdot 2$} \\
\hline $\mathrm{IRI}(\mu \mathrm{U} / \mathrm{ml})$ & & $13 \cdot 8$ & & $98 \cdot 0$ & $84 \cdot 6$ & $137 \cdot 4$ & $126 \cdot 7$ & \\
\hline Arginine stimulation & $\mathrm{GH}(\mathbf{n g} / \mathrm{ml})$ & $5 \cdot 1$ & & 12 & 6.7 & 3.0 & $2 \cdot 0$ & \\
\hline Levodopa stimulation & $\mathrm{GH}(\mathbf{n g} / \mathrm{ml})$ & - & & - & - & - & - & \\
\hline GRF stimulation & $\mathrm{GH}(\mathrm{ng} / \mathrm{ml})$ & $1 \cdot 3$ & 12 & 23 & $9 \cdot 0$ & $3 \cdot 2$ & $2 \cdot 8$ & \\
\hline
\end{tabular}


glucose improved but still remained high (table).

One year after the operation, her weight remained around $68 \mathrm{~kg}$ and she had a normal appetite. Her menstrual cycle returned to normal. Post operative CT scan showed reduction in size of the third ventricle although the size of the lateral ventricle was unchanged.

\section{Discussion}

Bray and Gallagher ${ }^{2}$ reported eight cases of hypothalamic obesity and reviewed the literature. They found only one case of this type of obesity associated with hydrocephalus among the 120 cases they checked (including the eight they reported), and this was due to surgical intervention for the treatment of a ruptured cerebral aneurysm. They did not discuss the causal relationship between hydrocephalus and hypothalamic obesity.

Fifteen cases of non-tumoural aqueductal stenosis with obesity have been reported. ${ }^{3-5}$ Visual symptoms and endocrinological symptoms such as amenorrhea, polyuria, hypogonadism and dwarfism were associated in many of these cases, and marked enlargement of the third ventricle was noted by CT scan in all cases. Some of the 15 obese patients might have been classified as hypothalamic obesity due to hydrocephalus. However, no evidence was provided in these reports that hydrocephalus due to aqueductal stenosis was the cause of their condition.

Bray and Gallagher ${ }^{2}$ utilised the two criteria for the diagnosis of hypothalamic obesity in their study; 1) pathological evidence of damage involving the hypothalamus and 2) obesity arising from an acute gain in weight following this injury. They also listed hyperphagia, intractable hyperinsulaemia, impaired $\mathrm{GH}$ response to its stimuli (insulin induced hypoglycaemia and arginine), and abnormal reproductive function including amenorrhea as the characteristics of hypothalamic obesity. The present case meets all of these criteria. In addition we have other evidence which strengthens the diagnosis of hypothalamic obesity. The patient showed normal GH response to GRF in the preoperative state, although she showed impaired $\mathrm{GH}$ response to arginine and levodopa. It is well documented that $\mathrm{GH}$ response to arginine, levodopa and GRF are impaired in simple obesity. ${ }^{6-8}$ In GH release,
GRF acts on the pituitary, ${ }^{\circ}$ whereas arginine or levodopa acts within the hypothalamus. ${ }^{78}$

In experimental animals, we have recently found that GH response to GRF was normal in ventromedial hypothalamic obesity whereas to arginine or levodopa it was impaired..$^{910}$ These results imply that $\mathrm{GH}$ release from the pituitary is preserved in hypothalamic obesity. In our case, we observed the exact same phenomenon in $\mathrm{GH}$ release in the preoperative state.

Hydrocephalus caused by aqueductal stenosis might have produced the hypothalamic obesity in this patient since hyperphagia and obesity were improved as well as reduction in size of the third ventricle after the shunting operation. The increased appetite after semistarvation treatment and the enlarged third ventricle suggested ventromedial hypothalamic damage, and this was the reason we decided to perform the operation. After the operation hyperphagia was relieved and her weight declined. We did not measure the pressure of CSF in either the pre- or postoperative state; however, CT scan findings and the clinical course strongly suggested that intraventricular pressure decreased after the operation.

1 Bray GA, York DA. Hypothalamic and genetic obesity in experimental animals: an autonomic and endocrine hypothesis. Physiol Rev 1979;59:719-809.

2 Bray GA, Gallagher TF Jr. Manifestation of hypothalamic obesity in man. A comprehensive investigation of eight
patients and a review of the literature. Medicine 1975;54:301-30.

3 Avman N, Erdogan G, Kanpolat Y. Pituitary pseudotumor. Surg Neurol 1978;9:107-11.

4 Daita G, Nakagawa Y, Satoh M, Nakagawa K, Kunita H. A case of non-tumoral stenosis of the aqueduct cerebri. Brain Nerve 1972;25:1223-7.

5 Rotilio A, D'Avella D, De Blasi F, Del Vivo RE, Salar G, Carteri A. Disendocrine manifestations during non tumoral aqueductal stenosis. $J$ Neurosurg $S c i$ 1986;30: 71-6.

6 Kopelman PG, Noonan K, Goulton R. Impaired growth hormone response to growth hormone releasing factor and insulin-hypoglycaemia in obesity. Clin Endocrinol 1985;23:87-94.

7 Copinschi G, Wegienka LC, Hane S. Effect of arginine on serum levels of insulin and growth hormone in obese serum levels of insulin and growth
subjects. Metabolism 1967;16:485-91.

8 Laurian L, Oberman Z, Ayalon D. Under-responsiveness of growth hormone secretion after L-DOPA and deep sleep stimulation in obese subjects. ISR J Med Sci 1975;11: $482-7$

9 Wakabayashi I, Inoue, S, Satoh S, Tonegawa Y, Shibazaki $T$, Ling $N$. Effect of hypothalamic ventromedial lesions on plasma hormone response to growth hormone releasing factor in rats. Brain Res 1985;346:70-4.

10 Mori T, Egawa M, Inoue S, Takamura Y, Wakabayashi I. Growth hormone release in ventromedial hypothalamic lesioned rats. Proc 8th Congress, JASSO 1988;105-6. 